\title{
Impact of Boreal Summer Intraseasonal Oscillation on Environment of Tropical Cyclone Genesis over the Western North Pacific
}

\author{
Ryuji Yoshida $^{1}$, Yoshiyuki Kajikawa ${ }^{1}$, and Hirohiko Ishikawa ${ }^{2}$ \\ ${ }^{1}$ RIKEN, Advanced Institute for Computational Science, Kobe, Japan \\ ${ }^{2}$ Disaster Prevention Research Institute, Kyoto University, Kyoto, Japan
}

\begin{abstract}
The impact of intraseasonal oscillation on tropical cyclone genesis (TCG) over the western North Pacific during boreal summer was examined in association with categorized synoptic-scale low-level flow patterns. Five synoptic-scale flow patterns were considered as synoptic-scale environment connecting the large-scale intraseasonal oscillation and meso-scale TCG: a shear line, a confluence region, an easterly wave, a monsoon gyre, and a pre-existing tropical cyclone. The phase and amplitude of the boreal summer intraseasonal oscillation (BSISO) were used. It is found that the phase 7 was favorable for TCG associated with the shear line, and the phases 7 and 8 were also favorable for TCG associated with the confluence region. During the favorable phases for each flow pattern associated with TCG, the BSISO affected the large-scale zonal wind distribution, and the large-scale zonal wind forms synoptic-scale flow patterns over the suitable environment for TCG. The link between the intraseasonal oscillation and synoptic-scale flow patterns is an important factor in TCG.
\end{abstract}

(Citation: Yoshida, R., Y. Kajikawa, and H. Ishikawa, 2014: Impact of boreal summer intraseasonal oscillation on environment of tropical cyclone genesis over the Western North Pacific. SOLA, 10, 15-18, doi:10.2151/sola.2014-004).

\section{Introduction}

To understand the physical mechanisms governing tropical cyclone genesis (TCG) is one of the most challenging issues in tropical meteorology. Meso-scale organization process of TCG and its environmental conditions are still open questions. TCG is rather complicated spanning over multiple scales in both space and time. Meso-scale organization processes of TCG are identified in some typical synoptic-scale conditions, and these conditions are organized in a large-scale environment (Fudeyasu et al. 2010). Equatorial waves also have significant role on TCG. They enhance convective activity and low-level vorticity, and meso-scale disturbance in the waves sometimes develops into tropical cyclone (TC) (Dickinson and Molinari 2002; Aiyyer and Molinari 2003). Frank and Roundy (2006) discussed the importance of the way that anomalous waves affect the low-level vorticity. It is worthwhile to discuss organization of low-level vorticity from the view of low-level flow pattern. In TCG cases over the western North Pacific, synoptic-scale processes are categorized into five characteristic patterns, based on the low-level flow (Ritchie and Holland 1999). These are the shear line (SL), the confluence region (CR), the easterly wave (EW), the monsoon gyre (GY), and the pre-existing TC (PTC). Some flow patterns supply vorticity to meso-scale processes of TCG, and others assist the TCG processes. Yoshida and Ishikawa (2013) introduced an objective method to categorize the five patterns, and applied it to all 908 TCG cases from 1979 to 2008. They found that the SL most frequently associates with TCG (42\%), followed by CR and EW $(16 \%$ and $18 \%$, respectively). Mechanisms controlling this proportion are still an open question, and also it is important to know the background large-

Corresponding author: Ryuji Yoshida, RIKEN/Advanced Institute for Computational Science, 7-1-26 Minatojima-minami-machi, Chuo-ku, Kobe, Hyogo 650-0047, Japan. E-mail: ryoshida@riken.jp. (c)2014, the Meteorological Society of Japan. scale environment controlling the synoptic-scale flow processes.

Westerly winds in the Asian monsoon trough or waves in the trade winds are considered as the typical large-scale environment affecting TCG over the western North Pacific (Gray 1968, 1998). The Madden-Julian Oscillation (MJO; Madden and Julian 1994) is reported as one of a typical intraseasonal oscillation in largescale environments for TCG (Nakazawa 1988; Liebmann et al. 1994; Zhu et al. 2003). Camargo et al. (2009) evaluated the potential for TCG in the lifecycle of the MJO. They found that the most favorable phase of the MJO for TCG cases over the western Pacific was 6 or 7 in the Wheeler and Hendon diagram (Wheeler and Hendon 2004). Camargo et al. (2009) suggested that variations in relative humidity and vorticity significantly contribute to the creation of a TCG environment. In previous studies, however, it is not explicitly shown how the MJO modifies the TCG environment.

Ritchie and Holland (1999) described the roles of the monsoon trough and trade winds in the formation process of the synopticscale flow patterns. However the intraseasonal oscillation was not included in their scope. Although Camargo et al. (2009) found the favorable phases of the MJO for TCG, they did not link their results with synoptic-scale flow pattern. The most favorable phase would be different among the different synoptic-scale flow patterns. One example can be seen if we compare TCG on 29 September, 2007 and 14 October, 1983 (Fig. 1). In this figure, the boreal summer intraseasonal oscillation (BSISO) index was used to identify lifecycle of the intraseasonal oscillation. The TCG location of these cases was quite similar (around $120^{\circ} \mathrm{E}, 17^{\circ} \mathrm{N}$ ), and both occurred near the boundary between westerly and easterly winds. However, the BSISO phase and synoptic-scale flow pattern were different at the time of genesis; the former TCG was associated with SL, while the latter was associated with CR. This difference of favorable phase among synoptic-scale flow patterns should be clarified for better understanding of TCG mechanism. Therefore, in this study we investigate the impact of the BSISO on the synoptic-scale flow patterns and discuss the possible mechanism in relations between large-scale and synoptic-scale flows.

\section{Data and Analysis Methodology}

The genesis of each TC was defined using best-track data from the Joint Typhoon Warning Center. In total, 738 TCG cases are recorded during the months of May-November between 1979 and 2008. We also used the daily mean outgoing longwave radiation (OLR) data (Liebmann and Smith 1996) and the six-hourly wind data from the Japanese 25-year reanalysis (JRA-25)/Japan Meteorological Agency Climate Data Assimilation System (Onogi et al. 2007) for the period 1979-2008. A Lanczos band-pass filter (Duchon 1979) with cut-off periods of 25 and 90 days and 139 weights was applied to the OLR and wind data to extract the intraseasonal variability. Because the majority of TCG occurs during May-November in the western North Pacific, we calculated an index of the BSISO following Kikuchi et al. (2012) to highlight the dominant mode of the intraseasonal oscillation during the boreal summer. The lifecycle of the BSISO mode is constructed on the basis of a phase space consisting of the first two principal components of extended empirical orthogonal function (EEOF) analysis. The lifecycle of the BSISO is divided into eight phases. The convective anomaly associated with the BSISO propagates eastwards over the equatorial Indian Ocean and then northwards 

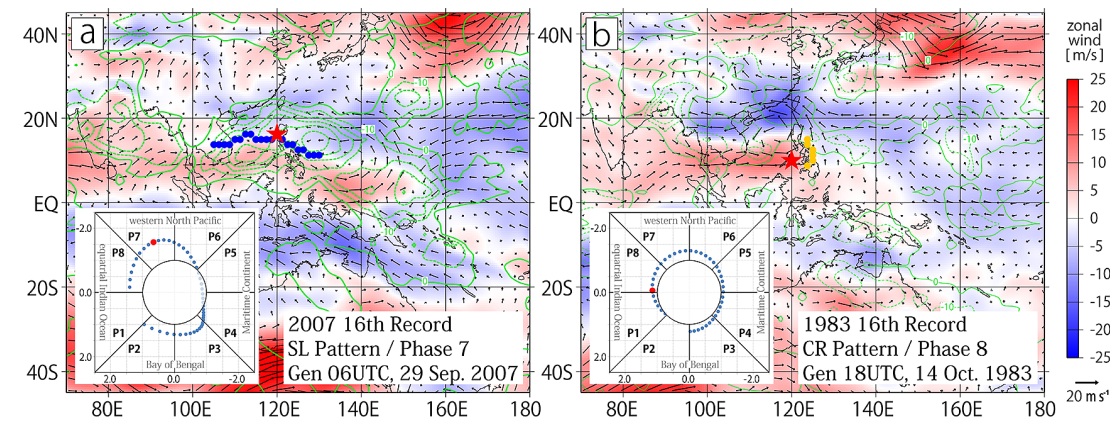

Fig. 1. TCG cases for the a) shear line and b) confluence regions and the active MJO. Blue dots (yellow dots) show shear line (confluence) detected by objective analysis. The wind fields (vectors) and zonal wind speeds (shading) at $850 \mathrm{hPa}$ three days before TCG are shown. The green contours are OLR anomalies $\left[\mathrm{W} \mathrm{m}^{-2}\right]$ from a 30 -year average. The red stars denote the locations of TCG. The bottom-left diagram in each panel is the daily trace of the phase diagram of the BSISO index, and the red dot is the time of TCG.

to the Philippine Sea. The positive convective anomaly is located over the western Pacific in phases 6 and 7, when the BSISO may have maximum influence on TCG in that region. The definition of the synoptic-scale flow pattern categories for TCG was the same as in Yoshida and Ishikawa (2013).

\section{Results and discussion}

Figure 2 shows the frequency of TCG cases in different phases of the BSISO index. The frequency is separately counted for the active and inactive BSISO, where active (inactive) is defined as the BSISO amplitude greater (less) than 1.0 at the genesis time. In each figure, TCG frequency is shown by different bar for active and inactive BSISO. TCG_TOTAL (Fig. 2a) denotes sum of all TCG cases, and the total number of TCG is 738. TCG TOTAL is classified into five categories associated with synoptic-scale flow patterns defined by Yoshida and Ishikawa (2013) (Fig. 2b-f). The frequencies of TCG cases associated with SL (hereafter, TCG SL), TCG_CR, TCG_EW, TCG_GY, and TCG_PTC are 318, 142, 133, 51, and 94, respectively. The red line and blue line in each panel show the threshold to judge significance of the value. The values of thresholds are defined as one standard deviation for each amplitude group and each flow pattern of TCG. This straightforward judgment is adopted instead of more rigorous statistical tests, since sample number is too small to conduct a reliable statistical test.

In Fig. 2a, the frequency of TCG cases in the active BSISO exceeds the threshold in phase 7, thus the most favorable phase of the TCG_TOTAL is judged as phase 7. Phases 5 and 6 are also favorable in the active BSISO. On the other hand, the frequency in the inactive BSISO does not have apparent favorable phases. This phase preference is consistent with the findings in Camargo et al. (2009). Of great interest is that the favorable phase for the TCG cases associated with each flow patterns deviates from that of TCG_TOTAL. The TCG_SL has frequency distribution similar to TCG_TOTAL and it favors phase 7 when the BSISO is active. The similarity of frequency distribution over different phases is attributed to the fact that the TCG_SL accounts for more than $40 \%$ of the TCG TOTAL cases. TCG_CR is the most favorable to occur in phase 7 and 8 with the active BSISO. The frequency of TCG_CR is considerably high even when the BSISO is inactive. Among them some cases are identified as occurred at the leading edge of westerly induced by pre-existing TC. TCG_EW cases distribute more broadly over different phases than TCG_SL and TCG_CR, and exhibits relatively high frequency in phases 3 to 5 in the inactive BSISO. High probability for TCG_GY is found in phases 5 and 6 in the active BSISO. The TCG PTC occurs in phases 7 and 8 in the inactive BSISO. A mature TC sometimes organizes a wave train to the southeast of itself through a mechanism of Rossby wave energy dispersion ( $\mathrm{Li}$ and $\mathrm{Fu} 2006$; $\mathrm{Li}$ et al. 2006). TCG_PTC takes place in such a wave train organized by a mature TC. Because TCG_TOTAL (i.e., candidates of a mature TC) has high probabilities in phases 7 (Fig. 2a), TCG_PTC has a high probability in the same or the following phases.

Now, we reversely discuss as that which TCG pattern is
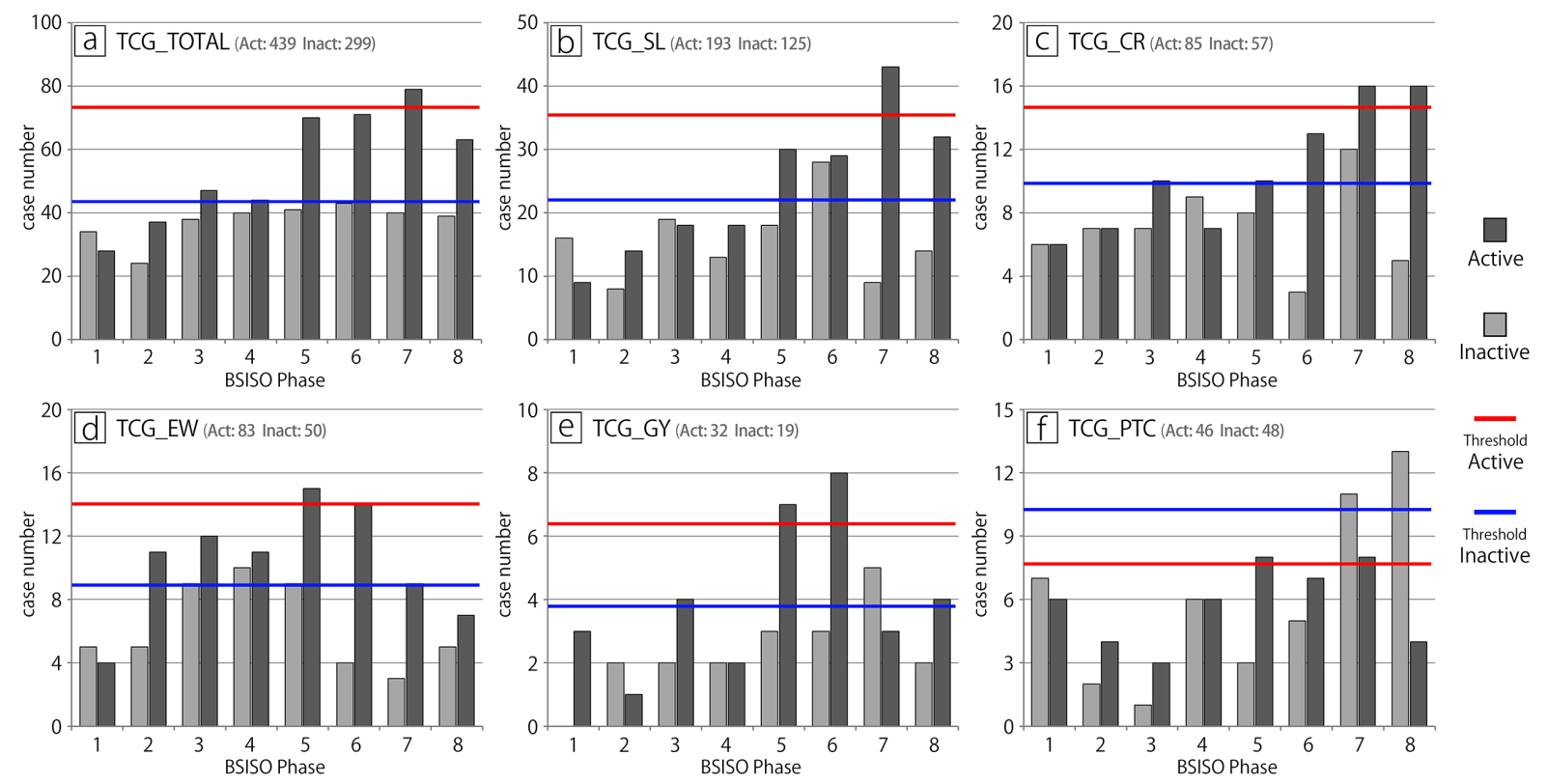

Fig. 2. Numbers of TCG cases during May to November from 1979 to 2008, which are divided into two groups (i.e. the active BSISO and the inactive BSISO). The SL, CR, EW, GY and PTC are for specific synoptic-scale flow patterns and the TOTAL is the sum. Two lines denote thresholds to judge a large number or not. The values of thresholds are defined as one standard deviation of each distribution for amplitude groups and flow patterns. Note that the range of vertical axis is different in each panel. 
favored by a specific BSISO phase. Discussion is given only for the TCG pattern which frequency is greater than the threshold, red line in Fig. 2. Figure 3 shows climatological distribution of largescale zonal wind and the average location of TCG in each phases. The superimposed contours show OLR anomaly from 'climatological' mean. To obtain 'climatological' field, the zonal wind and OLR-anomaly are averaged over May to November of 1979 to 2008 for only days with the active BSISO, and shown in the rectangle area covering the major TC genesis area, $5^{\circ} \mathrm{N}-20^{\circ} \mathrm{N}$ and $100^{\circ} \mathrm{E}-180^{\circ} \mathrm{E}$. The climatological TCG locations are also obtained by averaging TCG locations in the active BSISO over the same period. In each panel, the star indicates the average location of TCG_TOTAL. The averaged TCG positions for individual synoptic-scale flow pattern are computed in the same way and are shown by characters, S(SL), C(CR), E(EW), G(GY) and P(PTC). The bracket denotes that the TCG pattern has not significantly high frequency in the phase.

During phases 1 to 4 the center of the BSISO is in other longitudes, so that the convection is inactive over the western North Pacific as seen in positive OLR anomaly in Fig. 3. In phase 5 the center of the BSISO is in Maritime Continents, and the OLR anomaly turns to negative in the equatorial area. In phases 6 to 8 , it is seen that the center of convective activity shift to the north. Thus, the climatological fields reflect the feature of the BSISO. The large-scale westerly (easterly) wind is dominant around the star in phase 6 to 8 (in phase 3 to 5 ). This feature is consistent

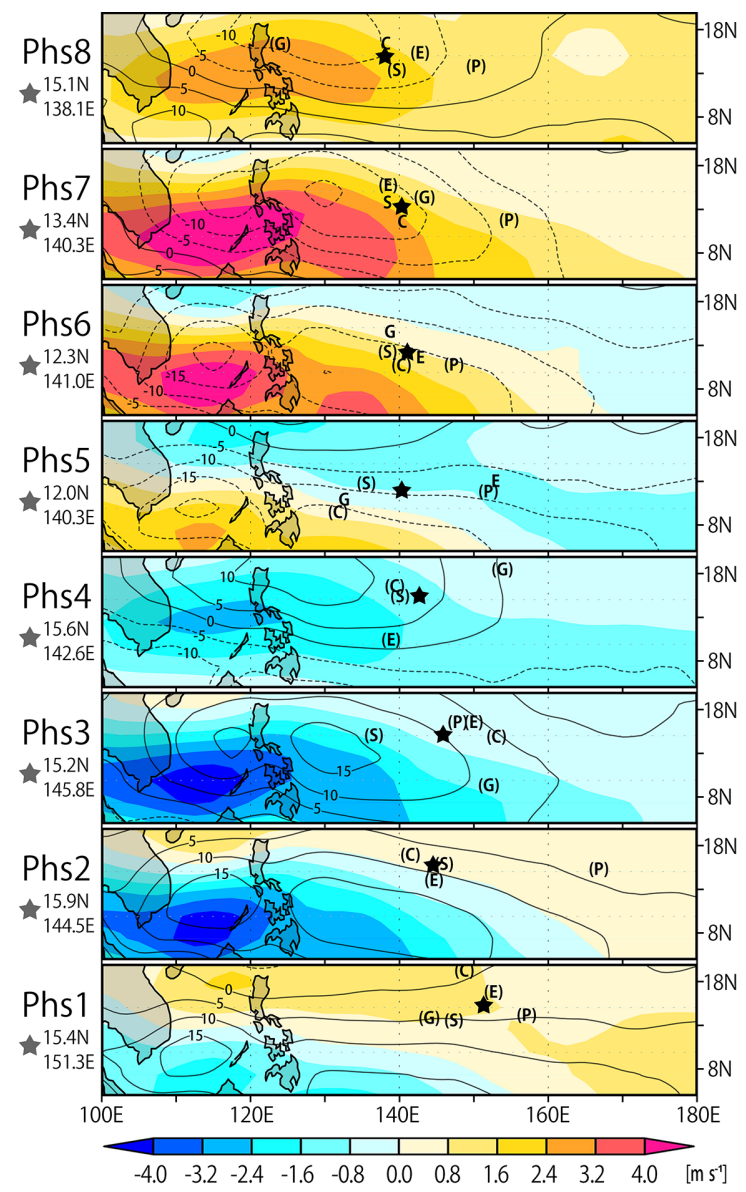

Fig. 3. $850 \mathrm{hPa}$ zonal wind field averaged in the active BSISO during May-November in 1979-2008 for each phase. Contours show averaged anomaly of OLR anomaly $\left[\mathrm{W} \mathrm{m}^{-2}\right]$ in the active BSISO from climatological mean. Stars indicate average locations of TCG_TOTAL in the phase with the active BSISO. Characters indicate average locations of TCG with the flow pattern; S: shear line, C: confluence region, E: easterly wave, G: monsoon gyre, and P: pre-existing TC. Blankets denote insignificant occurrence frequency. The zonal wind is filtered with 25-90 days bandpass filter before averaging. with the typical wind distribution associated with the BSISO discussed in Kemball-Cook and Wang (2001) and Kikuchi et al. (2012).

In phase 1 to 4 when the convection is relatively inactive over the TCG region, the averaged TCG locations are scattered in the eastern portion of the western North Pacific. In phase 5 when the BSISO migrates in between the eastern Indian Ocean and maritime continent from the west, convection becomes rather active. Westerly wind appears over the equatorial western Pacific, and cyclonic horizontal wind shear is enhanced between westerly wind and trade wind. Thus, the favorable environment appears over the western portion of the displayed area where the convection is active and the low-level vorticity is enhanced. Reflecting this, the average location moves to the west comparing with previous phases. The average location shifts to the north of the location in phase 5 during phase 6 to 8 following the shift of active convection and westerly wind associated with the BSISO. The high frequency of TCG in phase 5 to 8 shown in Fig. 2 seems to be consistent with active convection and distribution of large-scale flow in phase 5 to 8 .

We discuss the distribution of large-scale flow from a view of TCG_SL, TCG CR, and TCG_EW, which have larger sample of cases. In phase $\overline{7}$, large-scale westerly wind is climatologically strong over the west of the star, and likely to form synoptic-scale horizontal shear and confluence flow of zonal wind around the star. It seems that this distribution of zonal wind promotes the occurrence of TCG_SL and TCG_CR, and in fact, the $S$ and $C$ are plotted closely to the star in phase 7 . As well as phase 7, largescale westerly wind in phase 8 is strong over the area to the west of the star, and synoptic-scale confluence flow seems to be formed there. Thus, the $C$ is plotted near the star. On the other hand, large-scale easterly winds are dominant climatologically around the star in phase 3 to 5 . The large-scale environment which dominant easterly wind is not suitable for TCG SL and TCG CR, thus these patterns do not have high frequency in phase 3 to 5 as shown in Fig. 2b, c. In phase 5, which is the favorable phase for TCG $\mathrm{EW}$, easterly wind is remarkable in the northeast of the star, an $\overline{\mathrm{d}}$ the $E$ is plotted over the area where easterly wind is remarkable. In phase 3 or 4 , easterly wind is climatologically dominant over the equatorial western Pacific. However, convection is not strong enough to TCG in these phases. In phase 5, easterly wind is still prevailing and convection becomes active, and thus TCG_EW takes place. In the following phases after 5, convection is active enough but easterly wind shifts northwards.

It is revealed that large-scale flow tends to form the favorable background environment for the each synoptic-scale flow patterns corresponding with the favorable phases seen in Fig. 2. In order to see the impact of the BSISO clearer, we investigated whether large-scale flow associating with the active BSISO enhances synoptic-scale flow pattern or not. We discuss only for the TCG_SL and TCG_CR, which have larger frequencies than the other patterns. Figure 4 shows composited fields of zonal wind centering each locations of TCG SL and TCG CR dividing with activeness of the BSISO. Comparing TCG_SL in the active BSISO (Fig. 4a) and in the inactive BSISO (Fig. 4b), westerly wind to the southwest of the TCG location (a center of the figure) is stronger in the active BSISO than that in the inactive BSISO. It suggests that a stronger shear line is organized near the TCG location in the active BSISO. This is consistent with significant westerly winds in phase 7 with the active BSISO shown in Fig. 3. The westerly winds in the inactive BSISO would be controlled by the Asian-monsoon activity. Similar characteristic is found for TCG_CR by comparing Figs. 4c and 4d. Distributions of sea level pressure in TCG CR show that TCG_CR occurs at the eastern edge of the tropical trough. Westerly wind to the west of the TCG location is stronger in the active BSISO than in the inactive BSISO. Stronger westerly wind in the western side of the TCG location can intensify a zonal gradient of zonal wind, and it contributes to the TCG_CR.

Synoptic-scale low-level flow patterns in this study would correspond with the equatorial waves. Easterly wave corresponds with Tropical Depression (TD)-type disturbance. Dickinson and Molinari (2002) pointed out that many TD-type disturbance were 


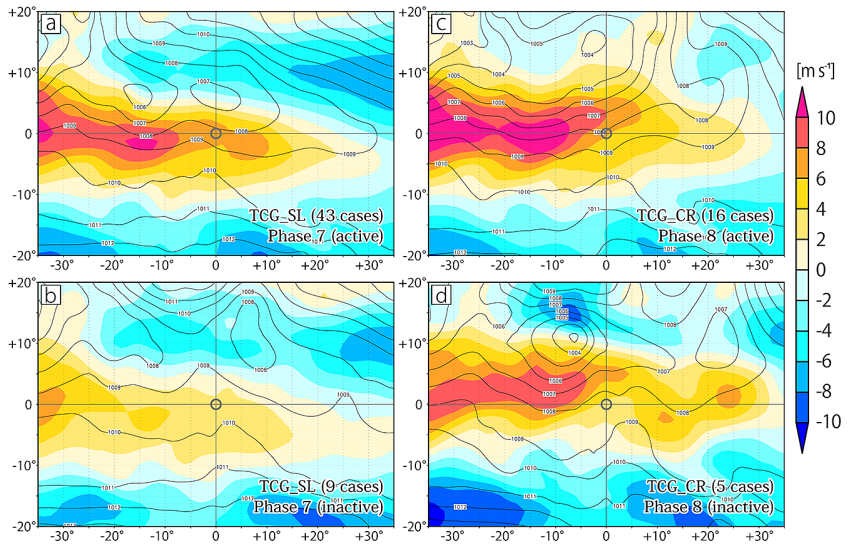

Fig. 4. Composited zonal wind field centering each TCG location; a) TCG SL in phase 7 of the active BSISO, b) TCG SL in phase 7 of the inactive one, c) TCG_CR in phase 8 of the active one, and d) TCG_CR in phase 8 of the inactive one. Color shade shows the zonal wind at $8 \overline{5} 0-\mathrm{hPa}$ height, and contours shows sea level pressure $[\mathrm{hPa}]$. Meteorological fields are 69 hours before each genesis time (averaged data in 66 and 72 hours before, but not filtered with 25-90 days bandpass filter). The objective TCG cases are from May to November, 1979 to 2008.

found in a zonal wind confluence, thus CR is also associated with TD-type disturbance. Mixed Rossby-gravity (MRG) wave transits to TD-type disturbance in an environment of active convection and zonal wind confluence, and then the TD-type disturbance develops into TC (Dickinson and Molinari 2002; Aiyyer and Molinari 2003). If we assume accordingly that TCG CR and TCG EW are associated with TD-type disturbance, they explain $27 \overline{5}$ TCG cases (37\% of total), and more than $60 \%$ of them occurred during the active BSISO. Though equatorial waves closely relate with TCG, it is not clear how much portion of TCG is triggered by equatorial waves. Frank and Roundy (2006) described that equatorial waves tend to organize large-scale cyclonic flow over the tropics, which eventually develops to TC. Since, the large-scale cyclonic flow is associated with organization of various types of low-level flow patterns, further study is necessary for addressing the relationship between low-level flow and various equatorial waves.

\section{Concluding Remarks}

We have described the impact of the BSISO, which is the dominant mode in the intraseasonal oscillation during boreal summer, on the synoptic-scale flow pattern of the TCG environment. It is found that the most favorable phases of the BSISO are different in each synoptic-scale flow pattern. In the BSISO, northward propagation of convection and associated wind field is dominant, in particular westerly winds shift northward after phase 5. Since the shear line and confluence region are organized at the northern and eastern edges of the westerly region respectively, the BSISO affects the position of the westerly winds and hence affects the TCG locations for TCG_SL and TCG_CR. The BSISO modulates the arrangement of westerlies such that the shear line coincides with active convections in phase 7 . On the other hand, the confluence region does so in phase 7 and 8. For TCG EW, the easterly winds blow over the broad area of the western North Pacific during phases 3 to 5 of the BSISO. For TCG_PTC, the frequency of a preexisting TC is the main controlling factor. Although the variety of synoptic-scale features in TCG is not treated in the investigation into the impact of the intraseasonal oscillation on TCG in prior studies, it is revealed by the current study that the favorable phases of the BSISO for TCG differ among synoptic-scale flow patterns. The manifestation of a linkage between the intraseasonal oscillation and the synoptic-scale flow pattern of TCG provides a better understanding and arrangement of the complicated processes of TCG.

\section{Acknowledgements}

The authors are grateful to the editor of SOLA and anonymous reviewers for their useful and critical comments, and also thank Dr. Yoshiaki Miyamoto, Dr. Tsuyoshi Yamaura, and Dr. Hirofumi Tomita for valuable discussions.

\section{References}

Aiyyer, A. R., and J. Molinari, 2003: Evolution of Mixed RossbyGravity Waves in Idealized MJO Environments. J. Atmos. Sci., 60, 2837-2855.

Camargo, S. J., M. C. Wheeler, and A. H. Sobel, 2009: Diagnosis of the MJO modulation of tropical cyclogenesis using an empirical index. $J$. Atmos. Sci., 66, 3061-3074.

Dickinson, M., and J. Molinari, 2002: Mixed Rossby-Gravity Waves and Western Pacific Tropical Cyclogenesis. Part I: Synoptic Evolution. J. Atmos. Sci., 59, 2183-2196.

Duchon, C. E., 1979: Lanczos filtering in one and two dimensions. J. Appl. Meteorol., 18, 1016-1022.

Frank, W. M., and P. E. Roundy, 2006: The Role of Tropical Waves in Tropical Cyclogenesis. Mon. Wea. Rev., 134, 2397-2417.

Fudeyasu, H., Y. Wang, M. Satoh, T. Nasuno, H. Miura, and W. Yanase, 2010: Multiscale interactions in the life cycle of a tropical cyclone simulated in a global cloud-system-resolving model. Part II: system-scale and mesoscale processes. Mon. Wea. Rev., 138, 43054327.

Gray, W. M., 1968: Global view of the origin of tropical disturbances and storms. Mon. Wea. Rev., 96, 669-700.

Gray, W. M., 1998: The formation of tropical cyclones. Meteorol. Atmos. Phys., 67, 37-69.

Kemball-Cook, S., and B. Wang, 2001: Equatorial waves and air-sea interaction in the boreal summer intraseasonal oscillation. J. Clim., 14, 2923-2942.

Kikuchi, K., B. Wang, and Y. Kajikawa, 2012: Bimodal representation of the tropical intraseasonal oscillation. Clim. Dyn., 38, 1989-2000.

Li, T., and B. Fu, 2006: Tropical cyclogenesis associated with Rossby wave energy dispersion of a preexisting typhoon. Part I: Satellite data analyses. J. Atmos. Sci., 63, 1377-1389.

Li, T., X. Ge, B. Wang, and Y. Zhu, 2006: Tropical cyclogenesis associated with Rossby wave energy dispersion of a preexisting typhoon. Part II: Numerical simulations. J. Atmos. Sci., 63, 1390-1409.

Liebmann, B., H. H. Hendon, and J. D. Glick, 1994: The relationship between tropical cyclones of the western Pacific and Indian Oceans and the Madden-Julian Oscillation. J. Meteor. Soc. Japan, 72, $401-411$.

Liebmann, B., and C. A. Smith, 1996: Description of a complete (interpolated) outgoing longwave radiation dataset. Bull. Am. Meteor. Soc., 77, 1275-1277.

Madden, R. A., and P. R. Julian, 1994: Observations of the 40-50-day tropical oscillation: a review. Mon. Wea. Rev., 122, 814-837.

Nakazawa, T., 1988: Tropical super clusters within intraseasonal variations over the western Pacific. J. Meteor. Soc. Japan, 66, 823-836.

Onogi, K., J. Tsutsui, H. Koide, M. Sakamoto, S. Kobayashi, H. Hatsushika, T. Matsumoto, N. Yamazaki, H. Kamahori, K. Takahashi, S. Kadokura, K. Wada, K. Kato, R. Oyama, T. Ose, N. Mannoji, and R. Taira, 2007: The JRA-25 reanalysis. J. Meteor. Soc. Japan, 85, $369-432$.

Reed, R. J., and E. E. Recker, 1971: Structure and properties of synoptic-scale wave disturbances in the equatorial western Pacific. $J$. Atmos. Sci., 28, 1117-1133.

Ritchie, E. A., and G. J. Holland, 1999: Large-scale patterns associated with tropical cyclogenesis in the western Pacific. Mon. Wea. Rev, 127, 2027-2043.

Serra, L. Y., G. N. Kiladis, and M. F. Cronin, 2008: Horizontal and vertical structure of easterly waves in the Pacific ITCZ. J. Atmos. Sci., 65, 1266-1284.

Wheeler, M. C., and H. H. Hendon, 2004: An all-season real-time multivariate MJO index: development of an index for monitoring and prediction. Mon. Wea. Rev., 132, 1917-1932.

Yoshida, R., and H. Ishikawa, 2013: Environmental factors contributing to tropical cyclone genesis over the western North Pacific. Mon. Wea. Rev., 141, 451-467.

Zhu, C., T. Nakazawa, and J. Li, 2003: Modulation of twin tropical cyclogenesis by the MJO westerly wind burst during the onset period of 1997/98 ENSO. Adv. in Atmos. Sci., 20, 882-898.

Manuscript received 22 November 2013, accepted 16 January 2014

SOLA: http://www.jstage.jst.go.jp/browse/sola/ 